\title{
Japanese Encephalitis Virus: An Emerging Pathogen
}

\author{
${ }^{1}$ Sneham Tiwari, ${ }^{1}$ Sai V.P. Chitti, ${ }^{2}$ Asha Mathur and ${ }^{1}$ Shailendra K. Saxena \\ ${ }^{1}$ Centre for Cellular and Molecular Biology, Uppal Road, Hyderabad 500007 (AP), India \\ ${ }^{2}$ Saraswati Medical and Dental College, Lucknow 227105 (UP), India
}

Received 2012-05-31, Revised 2012-07-25; Accepted 2012-08-02

\begin{abstract}
Japanese Encephalitis Virus (JEV) is a flavivirus maintained in a zoonotic cycle which involves pigs, birds and Culex species of mosquitoes causing fatal encephalitis endemic most of Asia and as far as Australia from its putative origin in Indonesia and Malaysia. The principle vector is Culex mosquito, most important being Culex tritaenorhynchus, present in greatest density in rainy season (June to November) Humans are accidental dead-end-hosts as they do not develop a level of viraemia sufficient to infect mosquitoes. The natural cycle of JEV consists of pig-mosquito-pig or bird-mosquito-bird and pigs serve as a biological amplifiers and reservoirs. The risk for Japanese encephalitis varies by appropriate ecological conditions and season to cause epidemics and epizootics. Disease control by vaccination is considered to be most effective. The Envelope (E) protein is dominant antigen including immunologic responses in infected host and eliciting virus neutralizing antibodies. Large scale immunization of susceptible human population is highly important to prevent this deadly infection. Attempts are being made to develop enhanced vaccines using the recombinant DNA technology. Since the existing inactivated, live attenuated or killed vaccines have side effects such as neurological disorders and systemic hypersensitivity, DNA based vaccines might aid the purpose of combating against JEV which are presently under clinical trials. Protection at personal level would help to reduce the incidence of the disease. In India vaccination against Japanese encephalitis are administered in areas where the disease is hyper-endemic.
\end{abstract}

Keywords: Japanese Encephalitis (JE), Epidemiology, Flavivirus, Transmission, Pathogenesis, Vaccination, Diagnostic Tools, Personal Hygiene, Large Scale Immunization

\section{INTRODUCTION}

Japanese encephalitis is mainly a pediatric disease (CDC, 2009) causing acute infection and inflammation of the brain. It is caused by Japanese encephalitis virus which belongs to arthropod-borne virus family and it is transmitted through Culex mosquito. JE was first recognized as a clinical entity in Japan in 1817, but the causative agent (JEV) was later isolated from a fetal human case in 1934 (Erlanger et al., 2009). JE was first reported in India in 1955 since than it has taken away thousands of lives. The total numbers of cases reported annually are about 35,000-50,000 (Zheng et al., 2012). Out of them $\sim 30-50 \%$ patients gets affected with neurological sequelae and 20-40 \% die (Singh et al., 2009; Nett et al., 2009). The natural cycle of JEV consists of Corresponding Author: Sneham Tiwari, Centre for Cellular and Molecular Biology, Uppal Road, Hyderabad 500007 (AP), India

pig-mosquito-pig or bird-mosquito-bird (Hurk et al., 2009) circulation of virus. When an infected mosquito bites a healthy individual, it may lead to a nonspecific febrile illness or a severe meningoencephalomyelities illness (Nemeth et al., 2010). In rainy season the incidences of the disease increases (Saxena et al., 2008). Hence high level of immunization is needed to prevent the wide spread of this disease amongst human population (Weaver and Reisen, 2009).

\subsection{Genome}

Japanese encephalitis virus is an RNA virus of Flaviviridae family. It measures around 40-50 $\mu \mathrm{m}$ in diameter and structurally it is spheroidal and of cubic symmetry. It is an enveloped virus having single stranded RNA as a genome which is infectious. The AJV 
genome is of $\sim 11 \mathrm{~kb}$ with positive polarity and a 5 , cap but it lacks a 3' poly tail. The genome can be divided into two parts: structural and Nonstructural (NS) genes. Structural genes are three in number and are involved in antigenicity since they are are expressed on the virus coded by capsid protein and involved in capsid formation: Core (C), pre Membrane (prM) and Envelope (E). Among all three the E gene is the most important and is the most studied one. There are seven NS genes: NS1, NS2a, NS2b, NS3, NS4a, NS4b, NS5 and these are involved in virus replication (Fig. 1). The viral RNA has noncoding regions of 95 and 585 bases at 5' and 3'ends which interacts with viral or host proteins which are important in virus replication (Vashist et al., 2011). A novel mutation in domain II of the envelop gene of JEV circulating in North India has been reported (Pujhari et al., 2011). The high rate of mutation in JEV is due to RNA dependent RNA polymerase (RdRp) coded by NS5 (Neyts et al., 1999). JEV replicates exclusively in the cytoplasm of infected cells, in a perinuclear location and matures on intracellular membranes.

\subsection{Epidemiology}

JE originated reportedly in Indonesia and Malaysia long back (Weaver et al., 1999; Sinniah, 1989). JE has spread extensively to several countries in Asia including both temperate- Japan, Korea, Taiwan, China and tropical countries like India, Sri Lanka, Bangladesh and Nepal (Bista and Shrestha, 2005). The cases of JE were also reported in newer geographical areas in the Torres Strait Islands of Australia (Kaur and Vrati, 2003) and in Papua New Guinea (Mackenzie et al., 2002). The reasons for this wide distribution is unclear but can be due to population shift or changes in climate, ecology, agricultural practices, animal husbandry or migratory birds patterns (Mackenzie et al., 2005; Saxena et al., 2011; Oya and Kurane, 2007).

In India, JE was first detected in India in 1955 and it is endemic in several parts such as Bihar, Uttar Pradesh, Assam, Manipur andhra Pradesh, Karnataka, Madhya Pradesh, Tamil Nadu, Haryana, Kerala, West Bengal, Orissa, Union territories of Goa and Pondicherry (Kabilan et al., 2004). The geographical area affected by JEV has expanded in the last 60 years with higher epidemic activity in North India and Central India (Ghosh and Basu, 2009). Almost $65 \mathrm{JE}$ cases from South India from 1956-1966 were reported by demonstrating specific neutralizing antibodies to JE. During 1978, several outbreaks of JE occurred in different parts of India viz. Burdwan and Bankura and adjoining areas of Bengal, Kolar district of Karnataka, Dhanbad district of Bihar, Dibrugarh district in Assam, Goa on the west coast and eastern districts of Uttar Pradesh, which was one of the worst JEV outbreaks. A successful isolation and identification of JE virus (GP78) as the causative agent was made from the brain tissue of a fatal case of encephalitis from Gorakhpur district for the first time in Lucknow (Mathur et al., 1982). Recently, another novel strain of JEV (GP05: NCBI accession no. FJ979830) was isolated during 2005 encephalitis outbreak in India (Saxena et al., 2009). Around 38 patient samples were tested to study the trend of the viral infection in north India (Saxena et al., 2009). Out breaks of JE was reported several times in many places of India including Haryana, Kerala, Bihar and several districts of Andhra Pradesh from 1988-2003.

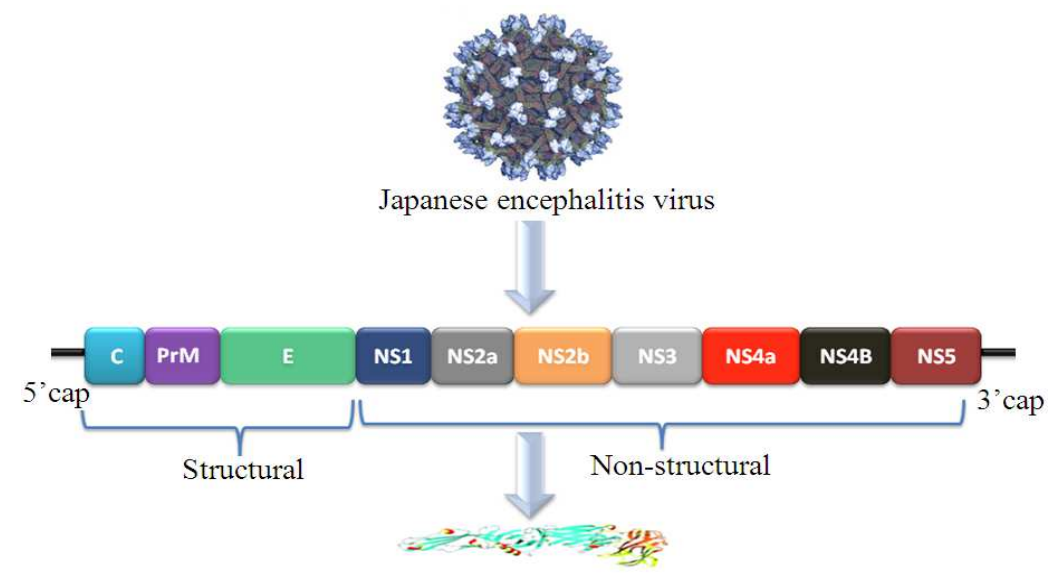

Fig. 1. Japanese Encephalitis Virus (JEV) morphology and a detailed display of the organisation of the viral genome - structural and non-structural genes and also the structure of the protein 


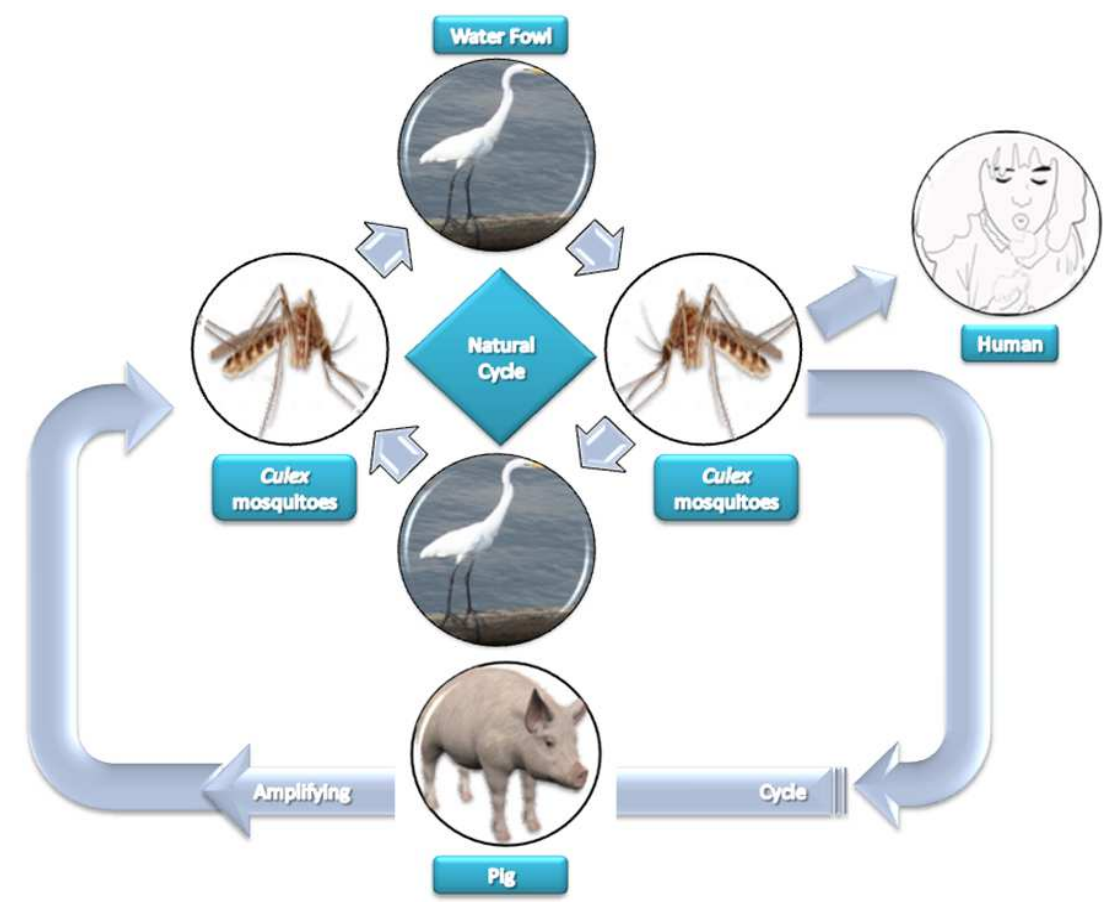

Fig. 2. Transmission cycle of Japanese encephalitis virus. JEV is transmitted in an enzootic cycle between Culex mosquitoes and amplifying vertebrate hosts, primarily pigs and wading birds like water fowls and egrets. Human beings serve as a dead-endhost in the JEV transmission cycle with low levels of viremia. Virus is not transmitted directly from human to human

In India the longest epidemic in three decades, had been reported during July to November 2005, in which more than 6,097 people were affected and approximately 1,398 died. Till date in Gorakhpur and around (in North India) several outbreaks of fatal Acute Encephalitis Syndrome (AES) were reported and approximately $>10-15 \%$ were caused by JEV.

\subsection{Transmission Cycle}

Japanese encephalitis virus is maintained in enzootic forms and appears as focal outbreaks under specific ecological conditions. They multiply in the tissues of arthropods without evidence of disease and damage. Man is an accidental, dead-end host fir JE. The principal vector species is Culex tritaeniorhynchus (Sucharit et al., 1989), which is a rural mosquito, present in great density in rainy season in both tropical and temperate regions. The other minor hosts are cattle, buffaloes, goats, sheep, horses, rodents, monkeys, dogs and bats. It has an extrinsic incubation period of 10-12 days. The natural cycle of JEV consists of pig-mosquito-pig or birdmosquito-bird cycles (Fig. 2). GIII was the only widely distributed genotype found in India until till when GI JEV strains were detected and isolated from 66 Acute
Encephalitis Syndrome (AES) patients along with GIII strains (Fulmali et al., 2011). This detection indicates their co-circulation and association with humans. In the mid 1990's genetic shift (Nabeshima et al., 2009) had occurred in Japan, Korea and Vietnam that lead to disappearance of GIII and then progressively GI supplanted it (Zhang et al., 2011a). In India exact mode of introduction of GI is not clear, but it is possible that it may have been introduced through migratory birds (Huang et al., 2010). Pigs are the most important biological amplifiers and reservoirs. Generally direct person to person spread of JEV does not or rarely occurs until it is through intrauterine transmission (Guy et al., 2010). Blood and organ transplantation also serve as a mode of transmission (Plesner, 2004). The risk for JE is more in rainy season both in temperate and tropical regions (Singh et al., 2012).

\subsection{Maternal to Foetal Transmission}

JEV infection transmits from mother to fetus through vertical mode of transmission. This may be due to persistent maternal infection or due to pregnancy induced reactivation of virus. An animal model of congenital infection with JEV has been described and 
transplacental transmission of the virus during consecutive pregnancies in mice has been shown experimentally (Mathur et al., 1982).

\subsection{Pathogenesis}

Japanese Encephalitis (JE) is now the foremost cause of viral CNS infection. JEV pathogenesis is still unclear (Yang et al., 2011). Since the variation exists in neurovirulence and peripheral pathogenicity among JE virus strains. After the infected mosquito bite, the virus enters into the reticulo-endothelial system and invades the central nervous system after the transient period of viremia. It distributes itself in hypothalamus, hippocampus, substantia nigra and medulla oblongata regions of brain via vascular endothelial cells by the mechanism of endocytosis which involves cholesterol and clathrin mediated pathways, referred to as lipid rafts acting as portals for virus entry (Das et al., 2010). The virus replicates in neurons and matures in the neuronal secretary system. Nearly $33 \%$ of JE infected patients die due to neurocysticercosis (NCC), suggesting that it may somehow predispose to JE (Desai et al., 1997). During acute stages congestion, edema, hemorrhagic symptoms are found in brain. Pathological changes in the neural tissues have also been reported in lymphoid organs and immune cells such as spleen and kupffer cells respectively.

\subsection{Host Immune Responses}

The virus enters the neuro-parenchyma by crossing capillary walls in the brain and distributes itself in various parts of brain. Initially JE virus is partially destroyed at its site of entry and the remaining virus is disseminated by local and systemic extra neural replication leading to viremia. After primary infection with JEV, presence of IgM antibodies and Tlymphocytes are seen until 2 weeks approximately. But antibodies alone are neither capable of terminating the viremia nor preventing the subsequent infection. Pregnancy is known to cause immunosuppression and persistent maternal infection or pregnancy induced reactivation of the virus which causes foetal infection. Isolation of JEV from human placenta and foetuses has been reported. JEV can establish latency within different organs despite the presence of antiviral antibodies. A significant decrease in serum iron levels, a frequent feature of microbial invasion is observed during JE infection. An early influx of macrophages followed by neutrophils at the site of injury in different organs of humans and mice has been reported, which is correlated with the production of a neutrophil chemotactic macrophage derived factor MDF, with development of hypoglycemia. This chemotactic protein (MDF) has been shown to play a protective role in the host defense against JEV, through production of reactive oxygen intermediates in neutrophils and reactive nitrogen oxide species degrading the virus protein and RNA.

\subsection{Signs and Symptoms}

The disease affects all the age groups, predominantly in children under 15 years of age (CDC, 2011). Sex distribution of a patient shows slight male predominance with the male: female ratio being approximately $\sim 1.5-1$ to $2-1$. Death in JE patients is usually seen within $24-48 \mathrm{~h}$ of admission. Among survivors, one in 200 affected individuals develop severe psycho neurological sequelae (Solomon and Winter, 2004) in the form of parkinsonism, convulsive disorders, motor abnormalities, impaired intellect, hearing deficit, scholastic backwardness, speech disturbances, other subtle neurological signs and movement disorders. There is alteration in plasma glucose levels found in the JEV positive patients (Tandon et al., 2002). Incubation period is 6-16 days among effected patients and symptoms have been given in Table 1 .

\subsection{Diagnosis}

With the advent of monoclonal antibodies as potential diagnostic tool (Chavez et al., 2010), the rapid detection of JE antigen in cerebrospinal fluid has become possible. The different diagnostic tests have been given in Table 2. However, the most rapid and potential diagnostic tool (Ishida et al., 2002) for JE diagnosis have been shown to be MAC-ELISA (Robinson et al., 2010) and indirect fluorescent antibody. MRI of the brain can also be used in diagnosis. MRI changes can be co-related (Misra and Kalita, 2010) with the type of encephalitis and duration of illness.

\subsection{Treatment and Prevention}

There is no specific treatment or anti-viral agent for JEV infection, it is proving to be a persistent threat. Monoclonal antibodies (Yamanaka et al., 2010), corticosteroids, interferon $\alpha-2 \mathrm{a}$ or ribavirin were not that effective in clinical outcome. The effect of Rosamarinic Acid (RA) has been shown as an effective anti-viral agent that reduces JE viral load along with proinflammatory cytokines in experimental animal (Swarup et al., 2007). Neutrophils have been also shown to have degradative effect on JEV (Srivastava et al., 1999). Usage of anti-sense molecules (vivo-morpholino) directed against the viral genome, in combating the virus through inhibiting viral replication has been demonstrated (Nazmi et al., 2010). Mycophenolic acid (Sebastian et al., 2011) inhibits JE virus by inhibiting its replication. List of different available vaccines (Lewthwaite et al., 2010) have been given in Table 3. 
Table 1. Duration, Signs and Symptoms of Japanese encephalitis

\begin{tabular}{lll}
\hline Disease course & Incubation duration & Signs and symptoms \\
\hline Prodromal stage & $1-6$ days & $\begin{array}{l}\text { General malaise, anorexia, headache, fever, vomiting. In } \\
\text { children diarrhoea and abdominal pain may be prominent. } \\
\text { Photophobia, hyperexcitability, focal and neurological signs, } \\
\text { muscular rigidity, dull, mask-like-face, tremulous eye movements, } \\
\text { cranial nerve palsies, loss of co-ordination, pathological } \\
\text { reflexes and in severe cases leads to coma. }\end{array}$ \\
$\begin{array}{ll}\text { Fever subsides, neurological signs tend to improve, } \\
\text { temperature rises to } 42^{\circ} \mathrm{C} \text { and eventually death occurs. } \\
\text { Late convalescent stage }\end{array}$ & If no death, it leads to long term psychoneurological sequelae \\
\hline
\end{tabular}

Table 2. Laboratory Diagnostic tools for Japanese encephalitis

\begin{tabular}{ll}
\hline Diagnostic tool & Detects \\
\hline $\begin{array}{l}\text { MAC-ELISA } \\
\text { Reverse passive }\end{array}$ & IgM antibodies \\
$\begin{array}{l}\text { Soluble JEV } \\
\text { andirect immune } \\
\text { fluorescence test }\end{array}$ & $\begin{array}{l}\text { Cell bound JEV antigen } \\
\text { Rapid micro } \\
\text { neutralization test }\end{array}$ \\
$\begin{array}{l}\text { Reverse } \\
\text { transcriptase PCR }\end{array}$ & $\begin{array}{l}\text { Neutralizing antibodies } \\
\text { to JEV in CSF }\end{array}$ \\
\hline
\end{tabular}

Table 3. Comparison of vaccines for Japanese encephalitis

\begin{tabular}{|c|c|c|}
\hline Vaccine & Source & Side effects \\
\hline $\begin{array}{l}\text { Formalin-inactivated } \\
\text { mouse brain derived }\end{array}$ & $\begin{array}{l}\text { Nakayama } \\
\text { strain }\end{array}$ & $\begin{array}{l}\text { Exper } \\
\text { effect }\end{array}$ \\
\hline $\begin{array}{l}\text { Inactivated hamster } \\
\text { kidney cell vaccine }\end{array}$ & Beijing strain & $\begin{array}{l}\text { Very low side } \\
\text { effects reported. }\end{array}$ \\
\hline $\begin{array}{l}\text { Live attenuated hamster } \\
\text { kidney cell line vaccine }\end{array}$ & $\begin{array}{l}\text { SA14-14-2 } \\
\text { strain, China }\end{array}$ & $\begin{array}{l}\text { Expensive with very } \\
\text { low side effects reported }\end{array}$ \\
\hline
\end{tabular}

Prevention methods are very important for minimizing JE infection (Saxena et al., 2006). Childhood Immunization is done by using inactivated mouse brainderived vaccine which is based on either the Nakayama or Beijing strains of the JE virus, the cell culture derived, inactivated JE vaccine based on the Beijing P-3 strain; and the cell cultures derived, live-attenuated vaccine based on the SA 14-14-2 strain (Halstead and Thomas, 2011) of the JE virus. Recombinant poxvirus vectors expressing the E and NS1 proteins of the JEV boosting a good immune response in mice models can be used as a vaccine. The prevention of vector-man contact is very good preventive method this can be done by eliminating potential mosquito breeding areas, environmental sanitation, waste water management by treating the water with larvicide either by Gambusa (larva-eating fish), drying and wetting of rice fields, frequent vaccination should be implemented and as well as personal protective measures. Reports have shown that induction of nitric oxide synthase plays a protective role against JEV (Saxena et al., 2001; 2000). Diethyldithiocarbamate has been also experimentally shown to inhibit JEV infection (Saxena et al., 2003). Future predictions of the disease and drug designing can be enhanced by computer aided design databases, which can design in silico the most efficient drugs which can be tested experimentally and then can be clinically tried. For the development of appropriate and effective therapy there is an immediate need to understand host factors role in JEV-induced neuropathogenesis (Gupta et al., 2010).

\subsection{Vaccination}

Through vaccination in the last five year, JE has been effectively controlled and eliminated in China, Japan, Taiwan and Korea (Chung et al., 2007; Takahashi et al., 2000; Jelinek, 2009). Second generation recombinant vaccines (Nalca et al., 2003) are also being developed, where genes encoding Prm and E proteins are packed into vectors. DNA based JEV vaccines which may be very efficient against the virus (Stephenson, 1998) are under clinical trials. DNAzymes (DZs) that cleave the RNA sequence of the 3'-NCR of JEV genome in vitro, on intra-cerebral administration in JE infected mice almost completely inhibit virus replication in the brain. Use of neutralizing bodies for vaccine designing may also serve the process (Markoff, 2000).

\section{CONCLUSION}

Viral encephalitis is the most common CNS infection, causing acute infection of the brain especially in children less than 15 years of age. It has proved to be a massive disaster globally taking several thousands of lives. Intense research for the knowabouts of the virus is carried in several countries, devising strategies to fight with the virus. In the last four decades, JE has been virtually eliminated in most of the countries after the immunization with inactivated mouse brain-derived vaccine. Unfortunately, there is no treatment for JE. Protection at the personal level would help to reduce the incidence of disease. Development of specific antivirals and vaccine should be taken up at a higher priority. 
Mosquito control is the sole available preventive measure for JEV transmission.

\subsection{Future Implications}

As JE is proving as a huge disastrous disease, research on JEV should be initiated at much wider scale, which should include development of effective anti-viral agents and vaccine strategies (Zhang et al., 2011b). Immunization is needed in JE prone areas (Rao, 2001). The virus is needed to be studied carefully, so that effective antivirals can be developed to target one of the stages in its life cycle. Over use of the vaccines should be avoided otherwise the virus might develop resistance against drugs which are administered frequently. It is also necessary to elucidate the ecology of migrating reservoir animals. Quarantine checks should be done at international immigration and emigration points, to keep a check on the spread of virus via foreign travelers. Vector control program should be effective enough to combat the risk. General awareness camps would be a good option to spread alertness in the local population level, to keep personal as well as surrounding areas and neighborhood clean and hygienic. Awareness campaign can educate people about the hygienic management and preventive measures which would immensely help in reducing disease incidences. Systematic approach is the need of hour, with the joint efforts of scientists, molecular biologists, doctors, drug developers, policy makers and local population to combat against the virus. A high sense of urgency is required to address this matter.

\section{ACKNOWLEDGMENT}

Researchers are grateful to Council of Scientific and Industrial Research (CSIR-CCMB), India for the encouragement and support for this study. NIH Awards (R37DA025576; R01MH085259) also supports SK Saxena and MPN Nair.

\section{REFERENCES}

Bista, M.B. and J.M. Shrestha, 2005. Epidemiological situation of Japanese encephalitis in Nepal. J. Nepal Med. Assoc., 44: 51-56. PMID: 16554872

CDC, 2009. Japanese encephalitis among three U.S. Travelers Returning from Asia, 2003-2008. MMWR Morb. Mortal. Wkly. Rep., 58: 737-740. PMID: 19609246

CDC, 2011. Recommendations for use of a booster dose of inactivated vero cell culture-derived Japanese encephalitis vaccine: Advisory committee on immunization practices. MMWR Morb. Mortal Wkly. Rep., 60: 661-663. PMID: 21617632
Chavez, J.H., J.R. Silva, A.A. Amarilla and L.T. Moraes Figueiredo, 2010. Domain III peptides from flavivirus envelope protein are useful antigens for serologic diagnosis and targets for immunization. Biologicals, 38: 613-618. PMID: 20817489

Chung, C.C., S.S. Lee, Y.S. Chen, H.C. Tsai and S.R. Wann et al., 2007. Acute flaccid paralysis as an unusual presenting symptom of Japanese encephalitis: A case report and review of the literature. Infection, 35: 30-32. PMID: 17297587

Das, S., S. Chakraborty and A. Basu, 2010. Critical role of lipid rafts in virus entry and activation of phosphoinositide 3' kinase/Akt signaling during early stages of Japanese encephalitis virus infection in neural stem/progenitor cells. J. Neurochem, 115: 537-549. PMID: 20722967

Desai, A., S.K. Shankar, P.N. Jayakumar, A. Chandramuki and M. Gourie-Devi et al., 1997. Coexistence of cerebral cysticercosis with Japanese encephalitis: A prognostic modulator. Epidemiol. Infect., 118: 165-171. PMID: 9129593

Erlanger, T.E., S. Weiss, J. Keiser, J. Utzinger and K. Wiedenmayer, 2009. Past, present and future of Japanese encephalitis. Emerg. Infect. Dis., 15: 1-7. PMID: 19116041

Fulmali, P.V., G.N. Sapkal, S. Athawale, M.M. Gore and A.C. Mishra et al., 2011. Introduction of Japanese encephalitis virus genotype I, India. Emerg. Infect. Dis., 17: 319-321. PMID: 21291622

Ghosh, D. and A. Basu, 2009. Japanese encephalitis-a pathological and clinical perspective. PLoS Negl. Trop. Dis., 3: e437-e437. PMID: 19787040

Gupta, N., V. Lomash and P.V. Rao, 2010. Expression profile of Japanese encephalitis virus induced neuroinflammation and its implication in disease severity. J. Clin. Virol., 49: 4-10. PMID: 20637688

Guy, B., F. Guirakhoo, V. Barban, S. Higgs and T.P. Monath et al., 2010. Preclinical and clinical development of YFV 17D-based chimeric vaccines against dengue, West Nile and Japanese encephalitis viruses. Vaccine, 28: 632-649. PMID: 19808029

Halstead, S.B. and S.J. Thomas, 2011. New Japanese encephalitis vaccines: Alternatives to production in mouse brain. Expert Rev. Vaccines., 10: 355-364. PMID: 21434803

Huang, J.H., T.H. Lin, H.J. Teng, C.L. Su and K.H. Tsai et al., 2010. Molecular epidemiology of Japanese encephalitis virus, Taiwan. Emerg. Infect. Dis., 16: 876-878. PMID: 20409392

Hurk, A.F.V.D., S.A. Ritchie and J.S. Mackenzie, 2009. Ecology and geographical expansion of Japanese encephalitis virus. Ann. Rev. Entomol., 54: 17-35. PMID: 19067628 
Ishida, I., K. Tomizuka, H. Yoshida, T. Tahara, N. Takahashi and A. Ohguma et al., 2002. Production of human monoclonal and polyclonal antibodies in TransChromo animals. Cloning Stem Cells. 4: 91102. PMID: 12006160

Jelinek, T., 2009. Ixiaro: A new vaccine against Japanese encephalitis. Expert Rev. Vaccines., 8: 1501-1511. PMID: 19863241

Kabilan, L., R. Rajendran, N. Arunachalam, S. Ramesh and S. Srinivasan et al., 2004. Japanese encephalitis in India: An overview. Indian J. Pediatr, 71: 609615. PMID: 15280610

Kaur, R. and S. Vrati, 2003. Development of a recombinant vaccine against Japanese encephalitis. J. Neurovirol, 9: 421-431. PMID: 12907387

Lewthwaite, P., M.V. Shankar P.H. Tio, J. Daly and A. Last et al., 2010. Evaluation of two commercially available ELISAs for the diagnosis of Japanese encephalitis applied to field samples. Trop. Med. Int. Health. 15: 811-818. PMID: 20487425

Mackenzie, J.S., 2005. Emerging zoonotic encephalitis viruses: Lessons from Southeast Asia and Oceania. J. Neurovirol, 11: 434-440. PMID: 16287684

Mackenzie, J.S., A.D. Barrett and V. Deubel, 2002. The Japanese encephalitis serological group of flaviviruses: A brief introduction to the group. Curr. Top Microbiol. Immunol., 267: 1-10. PMID: 12082984

Markoff, L., 2000. Points to consider in the development of a surrogate for efficacy of novel Japanese encephalitis virus vaccines. Vaccine, 2: 26-32. PMID: 10821970

Mathur, A., U.C. Chaturvedi, H.O. Tandon, A.K. Agarwal and G.P. Mathur et al., 1982. Japanese encephalitis epidemic in Uttar Pradesh, India during 1978. Indian J. Med. Res., 75: 161-169. PMID: 6282743

Misra, U.K. and J. Kalita, 2010. Overview: Japanese encephalitis. Prog. Neurobiol., 91: 108-120. PMID: 20132860

Nabeshima, T., H.T. Loan, S. Inoue, M. Sumiyoshi and Y. Haruta et al., 2009. Evidence of frequent introductions of Japanese encephalitis virus from south-east Asia and continental East Asia to Japan. J. Gen. Virol., 90: 827-832. PMID: 19264633

Nalca, A., P.F. Fellows and C.A. Whitehouse, 2003. Vaccines and animal models for arboviral encephalitides. Antiviral Res., 60: 153-174. PMID: 14638392
Nazmi, A., K. Dutta and A. Basu, 2010. Antiviral and neuroprotective role of octaguanidinium dendrimerconjugated morpholino oligomers in Japanese encephalitis. PLoS Negl. Trop. Dis., 4: e892-e892. PMID: 21124882

Nemeth, N.M., A.M. Bosco-Lauth, R.H. Sciulli, R.B. Gose and M.T. Nagata et al., 2010. Serosurveillance for Japanese encephalitis and West Nile viruses in resident birds in Hawai'i. J. Wildl. Dis., 2: 659-664. PMID: 20688669

Nett, R.J., G.L. Campbell and W.K. Reisen, 2009. Potential for the emergence of Japanese encephalitis virus in California. Vector Borne Zoonotic Dis., 9: 511-517. PMID: 18973447

Neyts, J., P. Leyssen and E.D. Clercq, 1999. Infections with flaviviridae. Verh. K. Acad. Geneeskd. Belg., 61: 661-697. PMID: 10655776

Oya, A. and I. Kurane, 2007. Japanese encephalitis for a reference to international travelers. J. Travel Med., 14: 259-268. PMID: 17617849

Plesner, A.M., 2004. Allergic reactions to Japanese encephalitis vaccine. Immunol. Allergy Clin. North Am., 23: 665-697. PMID: 14753386

Pujhari, S.K., S. Prabhakar, R.K. Ratho, M. Modi and M. Sharma et al., 2011. A novel mutation (S227T) in domain II of the envelope gene of Japanese encephalitis virus circulating in North India. Epidemiol. Infect., 139: 849-856. PMID: 20727244

Rao, P.N., 2001. Japanese encephalitis. Indian Pediatr., 38: 1252-1264. PMID: 11721065

Robinson, J.S., D. Featherstone, R. Vasanthapuram, B.J. Biggerstaff and A. Desai et al., 2010. Evaluation of three commercially available Japanese encephalitis virus IgM enzyme-linked immunosorbent assays. Am. J. Trop. Med. Hyg., 83: 1146-1155. PMID: 21036854

Saxena, S.K., 2008. Japanese encephalitis: Perspectives and new developments. Future Neurol., 3: 515-521. DOI: $10.2217 / 14796708.3 .5 .515$

Saxena, S.K., A. Mathur and R.C. Srivastava, 2001. Induction of nitric oxide synthase during Japanese encephalitis virus infection: evidence of protective role. Arch. Biochem. Biophys., 391: 1-7. PMID: 11414678

Saxena, S.K., A. Mathur and R.C. Srivastava, 2003. Inhibition of Japanese encephalitis virus infection by diethyldithiocarbamate is independent of its antioxidant potential. Antivir. Chem. Chemother, 14: 91-98. PMID: 12856920 
Saxena, S.K., A. Singh and A. Mathur, 2000. Antiviral effect of nitric oxide during Japanese encephalitis virus infection. Int. J. Exp. Pathol., 81: 165-172. PMID: 10762444

Saxena, S.K., M. Singh, A.K. Pathak and A. Mathur, 2006. Reply to Encephalitis outbreak finds Indian officials unprepared. Nat. Med., 12: 269-270. PMID: 16520763

Saxena, S.K., N. Mishra, R. Saxena, M. Singh and A. Mathur, 2009. Trend of Japanese encephalitis in North India: Evidence from thirty-eight acute encephalitis cases and appraisal of niceties. J. Infect. Dev. Ctries, 3: 517-530. PMID: 19762970

Saxena, S.K., S. Tiwari, R. Saxena, A. Mathur and M.P.N. Nair, 2011. Japanese Encephalitis: An Emerging and Spreading Arbovirosis. In: Flavivirus Encephalitis (Book), Ruzek, D. (Ed.), InTech, Croatia (European Union), ISBN-10: 9789533076690, pp: 295-316.

Sebastian, L., S.N. Madhusudana, V. Ravi and A. Desai, 2011. Mycophenolic acid inhibits replication of Japanese encephalitis virus. Chemotherapy, 57: 5661. PMID: 21282947

Singh, A., S.K. Saxena, A.K. Srivastava and A. Mathur, 2012. Japanese Encephalitis: A Persistent Threat. Proc. Natl. Acad. Sci. Sect B. Biol. Sci., 82: 55-68. DOI: $10.1007 / \mathrm{s} 40011-011-0005-\mathrm{x}$

Singh, A., S.K. Saxena, N. Mishra and A. Mathur, 2009. Neuromicrobiology in India. In: Neurosciences in India, Dhawan B.N. and P.K. Seth (Eds.). Indian Academy of Neurosciences (IAN) and Council of Scientific and Industrial Research (CSIR), India, pp: 269-318.

Sinniah, M., 1989. A review of Japanese-B virus encephalitis in Malaysia. Southeast Asian J. Trop. Med. Public Health, 20: 581-585. PMID: 2561714

Solomon, T. and P.M. Winter, 2004. Neurovirulence and host factors in flavivirus encephalitis-evidence from clinical epidemiology. Arch. Virol. Suppl., 161-170. PMID: 15119771

Srivastava, S., N. Khanna, S.K. Saxena, A. Singh and A. Mathur et al., 1999. Degradation of Japanese encephalitis virus by neutrophils. Int. J. Exp. Pathol., 80: 17-24. PMID: 10365083

Stephenson, J., 1998. Defective adenoviruses as novel vaccines for the Flaviviridae. Clin. Diagn. Virol., 10: 187-194. PMID: 9741645

Sucharit, S., K. Surathin and S.R. Shrestha, 1989. Vectors of Japanese Encephalitis Virus (JEV): Species complexes of the vectors. Southeast Asian .J Trop. Med Public Health, 20: 611-621. PMID: 2576966
Swarup, V., J. Ghosh, S. Ghosh, A. Saxena and A. Basu, 2007. Antiviral and anti-inflammatory effects of rosmarinic acid in an experimental murine model of Japanese encephalitis. Antimicrob. Agents Chemother, 51: 3367-3370. PMID: 17576830

Takahashi, H., V. Pool, T.F. Tsai and R.T. Chen, 2000. Adverse events after Japanese encephalitis vaccination: Review of post-marketing surveillance data from Japan and the United States. The VAERS working group. Vaccine, 18: 2963-2969. PMID: 10825597

Tandon, A., A. Singh, E. Atrishi, S.K. Saxena and A. Mathur, 2002. Alteration in plasma glucose levels in Japanese encephalitis patients. Int. J. Exp. Pathol., 83: 39-46. PMID: 12059908

Vashist, S., D. Bhullar and S. Vrati, 2011. La protein can simultaneously bind to both 30 - and 50-noncoding regions of Japanese encephalitis virus genome. DNA Cell Bio., 30: 339-346. PMID: 21294637

Weaver, S.C. and W.K. Reisen, 2009. Present and future arboviral threats. Antiviral Res., 85: 328-345. PMID: 19857523

Weaver, S.C., A.M. Powers, A.C. Brault and A.D. Barrett, 1999. Molecular epidemiological studies of veterinary arboviral encephalitides. Vet. J., 157: 123-138. PMID: 10204408

Yamanaka, A., K.C. Mulyatno, H. Susilowati, E. Hendrianto and T. Utsumi et al., 2010. Prevalence of antibodies to Japanese encephalitis virus among pigs in Bali and East Java, Indonesia, 2008. Jpn. J. Infect. Dis., 63: 58-60. PMID: 20093765

Yang, Y., J. Ye, X. Yang, R. Jiang and H. Chen et al., 2011. Japanese encephalitis virus infection induces changes of mRNA profile of mouse spleen and brain. Virol. J., 8: 80. PMID: 21345237

Zhang, J.S., Q.M. Zhao, X.F. Guo, S.Q. Zuo and J.X. Cheng et al., 2011a. Isolation and genetic characteristics of human genotype 1 Japanese encephalitis virus, China, 2009. PLoS One, 6: e16418-e16418. PMID: 21283590

Zhang, S., Z. Yin, C. Suraratdecha, X. Liu and Y. Li et al., 2011b. Knowledge, attitudes and practices of caregivers regarding Japaneseencephalitis in Shaanxi Province, China. Public Health, 125: 79-83. PMID: 21288546

Zheng, Y., M. Li, H. Wang and G. Liang, 2012. Japanese encephalitis and Japanese encephalitis virus in mainland China. Rev. Med. Virol. PMID: 22407526 